\title{
Grain Yield Performance and Stability of Quality Protein Maize Single Cross Hybrids in Mid-altitude Environment in Uganda
}

\author{
J. Ayiga-Aluba ${ }^{1}$, G. Asea ${ }^{2}$, D. B. Kwemoi ${ }^{2}$, G. Tusiime ${ }^{1} \&$ R. Edema ${ }^{1}$ \\ ${ }^{1}$ College of Agricultural and Environmental Sciences, Makerere University, Kampala, Uganda \\ ${ }^{2}$ National Crops Resources Research Institute (NaCRRI) Namulonge, Kampala, Uganda \\ Correspondence: Josephine Ayiga Aluba, Department of Agriculture, Kyambogo University, P.O. Box 1, \\ Kyambogo, Kampala, Uganda. Tel: 256-772-627-748. E-mail: joseayiga@yahoo.com
}

\author{
Received: May 2, $2018 \quad$ Accepted: June 17, $2018 \quad$ Online Published: August 15, 2018 \\ doi:10.5539/jas.v10n9p55 URL: https://doi.org/10.5539/jas.v10n9p55
}

\begin{abstract}
Stability in performance is important for determining adaptation and recommendation of pre-commercial crop varieties. This study was conducted with the following objectives: i) to determine stability of grain yield for 55 quality protein maize (QPM) single cross hybrids generated from 14 inbred lines ii) to determine the pattern of grouping of QPM hybrids and test environments based on grain yield response. The test hybrids were generated during the second season of 2015 and evaluated in three agro-ecological zones during the first season of 2016. Two checks were used: Longe 5D, a popular QPM hybrid and a top cross of Longe 5D with CML511. Additive main effects and multiplicative interaction (AMMI) and genotype and genotype by environment interaction (GGE) analyses were used to assess the stability of the hybrids. Results showed highly significant differences between genotypes, environments and GEI. The first principal component axis (IPCAI) was significant ( $p<$ 0.01 ) and accounted for $61.5 \%$ of the interaction effect. Both (IPCAI) and IPCAII) cumulatively contributed to entire degrees of freedom available for interaction component. Hybrid QPMSC-29 had the highest grain yield across environments. The AMMI biplot clearly depicted the genotypes on the bases of their adaptation patterns. Hybrids QPMSC-43, QPMSC-12, QPMSC-18 and QPMSC-29 were found to be more stable and responsive to favorable environments. Among them QPMSC-18 was more stable across locations. The AMMI biplot successfully identified 2 mega-environments as Namulonge and Bulindi in the first mega-environment with QPMSC-29 as the winning genotype and Masaka as the second mega-environment with QPMSC-10 as the winning genotypes. Hybrid, QPMSC-46 was an ideal genotype with above average score for grain yield. The single cross hybrids QPMSC-29, QPMSC-18 and QPMSC-10 were identified as stable yielder across environments in addition to higher yield. These hybrids can be recommended for all the three locations, for cultivation.
\end{abstract}

Keywords: QPM hybrids, G×E Interaction, AMMI, GGE biplot, grain yield

\section{Introduction}

Maize (Zea mays L.) is an important food, feed and cash crop in east and southern Africa (ESA) grown predominantly by small-scale farmers. In Uganda, more than $57 \%$ of the farming households engage in maize production (Haggblade \& Dewina, 2010). The average yields are generally less than $50 \%$ compared with the world average. The low yields are attributed to a number of factors including low use of improved seed, climate variability, and low use of fertilizers contributing to declining soil fertility and poor crop management practices. These productivity constraining factors vary among maize growing environments and seasons within a year leading to unpredictable food security situations. The phenomenon of differential genotype responses under varying environments referred to as genotype by environment interaction (GEI) is a problem that complicates the selection of superior genotypes because it results in the failure of genotypes to respond consistently in variable environmental conditions. Subsequently systematic evaluation of GEI effects for a given trait is useful for understanding varietal stability and hence strategic deployment of varieties (Acquaah, 2012), and has been exploited by breeders to identify and select more stable varieties recommended to farmers to reduce variability in performance from one production environment to another.

In maize breeding, the selection and choice of pipeline pre-commercial varieties is subject to two considerations: (1) high grain yield potential in a wide range of environments and (2) consistent performance over environments. 
It is for these reasons that several univariate and multivariate statistical models have been deployed for stability analysis and/or GEI (Eberhart \& Russell, 1966; Gauch et al., 2008; Gauch, 2013). In several published literature over the years, reviews highlighting weaknesses, strengths and best practices of the stability and/or GEI models have been undertaken (Crossa, 1990; Piepho, 1994; Ye et al., 2013). Additive main effect and multiplicative interaction (AMMI) and genotype and genotype-by environment (GGE) biplot methodology have recently gained popularity and are most preferred (Yan \& Kang, 2003; Badu-Apraku et al., 2013, 2015). AMMI allows exhaustive data analysis by performing regular analysis of variance (ANOVA) and estimating interaction effects through principal component analysis (PCA) which somewhat increases precision in trait estimates and enables reliable selections (Gauch et al., 2008; Hongyu et al., 2014). A complementary analytical tool to visualize GEI is the genotype plus genotype by environment (GGE) biplot (Yan \& Tinker, 2002). The polygon view of a GGE biplot, allows the assessment of the interaction patterns between genotypes and environments and effectively interprets a biplot (Yan \& Kang, 2002). Genotypes that occupy vertices of the polygon are the best performers for a given trait in a specific environment. The GGE biplot allows identification of stable and best performing genotypes in test environments which is an important decision-making tool for identifying crop varieties for subsequent release (Rao et al., 2011; Farshadfar et al., 2013). Grain yield being quantitative in nature routinely exhibits GEI. Several maize breeding programs constantly develop, evaluate and select the best performing maize varieties for the mid-altitude sub-humid agro-ecology of east and central African (ECA) countries. This is especially important in Uganda where the national average maize yields are very low at $2.7 \mathrm{t} \mathrm{ha}^{-1}$ (Country Variety Profiles, 2015), due to several production constraints, which are the major cause for the presence of GEI and low yield stability. This necessitates genotype evaluation in multi-environments trials (MET) before its commercial release (Annicchiarico, 2002; Kang et al., 2004; Fan et al., 2007). Stable performance of maize hybrids in multi-environment trials is critical to sustain food production. Quality Protein Maize (QPM) varieties released in Uganda are characterized by low productivity $\left(1.4 \mathrm{t} \mathrm{ha}^{-1}\right)$ and susceptibility to foliar diseases. There is no information on the GEI and stability in grain yield performance of newly bred QPM single cross hybrids developed in Uganda for different agro-ecological zones. Therefore, the objectives of the study were to investigate GEI and stability in performance for grain yield, among 53 new single QPM hybrids across three locations and to determine the pattern of grouping of the genotypes and the environments based on grain yield response.

\section{Materials and Methods}

The trial was conducted in three sites in Uganda: Bulindi $\left(1^{\circ} 25^{\prime} \mathrm{N}, 31^{\circ} 21^{\prime} \mathrm{E}\right.$; altitude $\left.1140 \mathrm{~m}\right)$, Masaka $\left(0^{\circ} 20^{\prime} \mathrm{S}\right.$, $31^{\circ} 44^{\prime} \mathrm{E}$; altitude $\left.1315 \mathrm{~m}\right)$ and Namulonge $\left(0^{\circ} 32^{\prime} \mathrm{N}, 32^{\circ} 35^{\prime} \mathrm{E}\right.$; altitude $\left.1150 \mathrm{~m}\right)$. These sites are located approximately $184 \mathrm{~km}$ northwest, $118 \mathrm{~km}$ Southwest and30 km North of Kampala, respectively. All the three locations experience a bimodal rainfall pattern, with the first season, A, from March to August and the $2^{\text {nd }}$ season, B, from September to December/January. These experimental sites are all hot spots for common foliar diseases in Uganda. Fourteen parental QPM inbred lines were crossed in a diallel fashion to synthesize 91 single crosses excluding reciprocal crosses, during the second season of 2015 at Namulonge. The list of the QPM lines used in the single cross hybrids are shown in table1. A total of 53 resultant single cross hybrids were evaluated together with two popular commercial checks. The first check was a top cross of Longe 5D with CML511 while check 2 was Longe 5D, a popular QPM hybrid. The single cross hybrids and the checks were planted in three agro-ecological zones in the country, during the first season of 2016. Field experiments were laid out following alpha lattice designs with two replications generated using the CIMMYT field book (Banziger \& Vivek, 2007) 
Table 1. QPM Lines used to generate 53 single cross hybrids

\begin{tabular}{ll}
\hline Line name & Pedigree \\
\hline QPML1 & Pool15QPMFS309-B-1-B-B-B-B-B-B-B \\
QPML2 & Pool15QPMFS309-B-5-B-\#-B-B-B-B-B-B \\
QPML3 & Pool15QPMFS440-B-5-B-B-B-B-B-B-B \\
QPML4 & QPM24 \\
QPML5 & Pool15QPMFS51-B-8-B-B-B-B-B-B \\
QPML6 & Pool15QPMFS538-B-3-B-B-B-B-B-B-B \\
QPML7 & Pool15QPMFS538-B-3-B-\#-5-1-1-B-B-B \\
QPML8 & Pool15QPMFS538-B-3-B-\#-5-1-2-B-B-B \\
QPML9 & Pool15QPMFS538-B-3-B-\#-5-1-3-B-B-B \\
QPML10 & Pool15QPMFS538-B-3-B-\#-5-1-4-B-B \\
QPML11 & Pool15QPMFS538-B-3-B-\#-5-3-1-B-B-B \\
QPML12 & Pool15QPMFS538-B-3-B-\#-5-4-1-B-B \\
QPML13 & Pool15QPMFS538-B-3-B-\#-5-4-2-B-B \\
QPML14 & Pool15QPMFS538-B-3-B-\#-7-1-1-B-B-B \\
QPML15 & Pool15QPMFS538-B-3-B-\#-7-1-2-B-B-B \\
QPML16 & Pool15QPMFS538-B-3-B-\#-7-1-3-B-B-B \\
QPML17 & Pool15QPMFS538-B-3-B-\#-7-3-2-B-B \\
QPML18 & Pool15QPMFS538-B-3-B-\#-7-4-1-B-B-B \\
QPML19 & Pool15QPMFS538-B-3-B-\#-7-4-2-B-B-B \\
QPML20 & Pool15QPMFS538-B-3-B-\#-7-5-1-B-B-B \\
QPML21 & Pool15QPMFS538-B-3-B-\#-7-5-2-B-B-B \\
QPML22 & Pool15QPMFS538-B-3-B-\#-7-6-1-B-B-B \\
QPML23 & Pool15QPMFS538-B-3-B-\#-7-6-2-B-B-B \\
QPML24 & Pool15QPMFS51-B-8-B-\#-B-B-B-B-B-B \\
\hline
\end{tabular}

\subsection{Data Collection}

Data on grain yield and other important agronomic traits were collected on plot and individual plant basis. Data collected on plot basis were for plant aspect, days to anthesis, disease score and grain yield.

Plant aspect (PA) were rated using a quantitative scale of $1-5$, where, 1 is very good and 5 is bad. Days to anthesis (DA) was counted as number of days from planting to when $50 \%$ of the plant in a plot shed pollen The most prevalent diseases such as Turcicum leaf blight, gray leaf spot, and maize streak were scored according to CIMMYT's standard disease rating (CIMMYT, 1985) scale of $1-5$, where, $1=$ very slight to slight no infection, one or two to few scattered lesions on lower leaves; 2 = light infection, moderate number of lesions on lower leaves only; 3 = moderate infection, abundant lesions on lower leaves, few on middle leaves; $4=$ heavy infection, lesions abundant on lower and middle leaves, extending to upper leaves; $5=$ very heavy infection, lesions abundant on almost all leaves, plants prematurely dry or killed by the disease.

For grain yield (GY), the total grain yield from all the ears of each experimental unit was recorded, then adjusted to $12.5 \%$ moisture level to estimate grain yield per hectare, using the formula according to Carangal et al. (1971) given below:

$$
\text { Grain yield ha }{ }^{-1}=(\mathrm{FW} \times 0.8) \times(100-\mathrm{M}) / 87.5 \times\left(10,000 \mathrm{~m}^{2} \mathrm{ha}^{-1} / 7.5 \mathrm{~m}^{2}\right)
$$

Where, $\mathrm{FW}=$ Field weight of ear in $\mathrm{kg} / \mathrm{plot}$ at the time of harvest; $0.8=$ threshing percentage; $\mathrm{M}=$ Percentage grain moisture at harvest; $87.5=100-$ Standard Moisture (12.5); $7.5=$ Plot area per row per cycle $(2 \times 5 \times 0.75$ $\mathrm{m})$.

Data on individual plant basis were taken for plant height, ear height, and ear aspect and grain texture. Plant height $(\mathrm{PH})$ was measured as the average height of five randomly selected plants measured in $\mathrm{cm}$ from base of the plant to the first tassel branch. The measurement was made two weeks after pollen shedding ceased. Ear height $(\mathrm{EH})$ was taken as the average height of five randomly selected plants measured in $\mathrm{cm}$ from base of the plant to the node bearing the upper most ear of the same plants. For ear aspect (EA), the assessment was done after harvesting. Ears for each genotype were arranged in the same orientation in such a way that all ears could be seen and scored at once. A scale of 1 to 5 was used, where, $1=$ very good, assigned to big uniform and appealing cobs with flint kernels; 2 = good, assigned to big fairly uniform cobs with less flint kernels; 3 = 
average, assigned to fairly uniform cobs of average size with semi-flint/semi-dent kernels; $4=$ poor, small non-uniform cobs with more of dent kernels; 5 = very poor, assigned to cobs with inferior characteristics such as small non-uniform cobs with gaps and/or uneven kernels. Grain texture (GT) was scored using a scale of 1-5, where, $1=100.0 \%$ shiny-flint kernels, $2=$ semi-flint (flint kernels with less than $25.0 \%$ dent kernels), $3=$ semi-flint-semi-dent (26.0 to $50.0 \%$ dent kernels), $4=$ semi-dent (51.0-75.0\% dent kernels), and dent (76.0 to $100.0 \%$ dent kernels).

\subsection{Data Analysis}

Yield data were subjected to AMMI and GGE biplot analyses using GenStat software version 14 (Payne, 2008). The AMMI model, which combines the standard analysis of variance with principal component analysis (Zobel et al., 1988), was used to investigate the magnitude of GEI. The AMMI model first fits additive effects for the main effects of genotypes and environments, using the additive analysis of variance procedure. Subsequently, the program fits multiplicative effects for GEI by principal component analysis (Zobel et al., 1988). Both AMMI and GGE biplot methods were used to investigate the G, E and GEI effects on grain yield of the maize hybrids. These methods were described in detail by Yan (2002), Yan and Hunt (2001), and Gauch (2006).

\section{Results and Discussion}

Data of the analysis of variance showed that grain yield was influenced by the environments of testing, genotypes and their interactions (Table 2). The later factor was of particular significance, since the presence of a reliable GEI $(p<0.05)$ allows further analysis. The AMMI analysis of variance of grain yield of the fifty five genotypes tested in three environments showed that $71.65 \%$ of the total sum of squares was attributable to genotypic effects, $10.51 \%$ to environmental effects and $17.83 \%$ to genotype $\times$ environment interaction effects (Table 2). This is in accordance with the report of Kaya et al. (2006); Farshadfar et al. (2012) and Mohamed et al. (2013). In their study, the effects of E, G and GEI accounted for $81,7.3$ and $11.7 \%$ of the total treatments variation respectively.

Table 2. AMMI analysis of variance for 55 QPM single cross hybrids evaluated in three environments in Uganda

\begin{tabular}{|c|c|c|c|c|c|c|c|c|c|c|c|c|c|}
\hline \multirow{2}{*}{ Source } & \multirow{2}{*}{ Df } & \multicolumn{12}{|c|}{ Mean squares } \\
\hline & & GY & TLB & AD & ASI & Rust & EA & EH & GT & GLS & $\mathbf{P H}$ & MSV & Ear Pos. \\
\hline Treatments & 164 & $8.17^{* * *}$ & $0.99^{* * *}$ & $24.5^{* * *}$ & $18.26^{* * *}$ & $0.51^{* * *}$ & $1.40^{* * *}$ & $373^{* * *}$ & $0.24^{* * *}$ & $0.49^{* *}$ & $1832^{* * *}$ & $0.61^{* * *}$ & $0.004^{* * *}$ \\
\hline Genotypes & 54 & $17.75^{* * *}$ & $0.42^{*}$ & $17.4^{* * *}$ & $13.03^{* * *}$ & $0.36^{* *}$ & $1.57^{* * *}$ & $636^{* * *}$ & $0.19^{* * *}$ & $0.55^{* *}$ & $2375^{* * *}$ & $0.34^{* * *}$ & $0.004^{* * *}$ \\
\hline Environments & 2 & $72.11^{* * *}$ & $50.02^{* * *}$ & $1291.8^{* * *}$ & $652.66^{* * *}$ & $14.19^{* *}$ & $56.26^{* * *}$ & $5598 \mathrm{~ns}$ & $7.01^{* * *}$ & $5.13^{\text {ns }}$ & $65227^{* * *}$ & $20.33^{* * *}$ & $0.057^{*}$ \\
\hline Block & 3 & $6.21^{* *}$ & $0.22^{\text {ns }}$ & $4.5^{\mathrm{ns}}$ & $67.68^{* * *}$ & $2.06^{* * *}$ & $0.67^{\mathrm{ns}}$ & $2166^{* * *}$ & $0.25^{*}$ & $1.73^{* *}$ & $5047^{* * *}$ & 0.04 & $0.012^{* * *}$ \\
\hline GEI & 108 & $2.2^{*}$ & $0.37^{\text {ns }}$ & $4.6^{\mathrm{ns}}$ & $9.13^{* * *}$ & $0.35^{* *}$ & $0.31^{\mathrm{ns}}$ & $144^{* * *}$ & $0.15^{* * *}$ & $0.38^{\text {ns }}$ & $387^{* *}$ & $0.37^{* * *}$ & $0.002^{* *}$ \\
\hline IPCA1 & 55 & $2.65^{* *}$ & $0.39^{\text {ns }}$ & $5.6^{*}$ & $15.49^{* * *}$ & $0.50^{* * *}$ & $0.45^{*}$ & $160^{* * *}$ & $0.25^{* * *}$ & $0.44^{*}$ & $439^{* *}$ & $0.59^{* * *}$ & $0.003^{* * *}$ \\
\hline IPCA2 & 53 & $1.73^{\mathrm{ns}}$ & $0.34^{\mathrm{ns}}$ & $3.5^{\mathrm{ns}}$ & $2.53^{\mathrm{ns}}$ & $0.17^{\mathrm{ns}}$ & $0.15^{\mathrm{ns}}$ & $127 * *$ & $0.04^{\mathrm{ns}}$ & $0.31^{\mathrm{ns}}$ & $332 *$ & 0.14 & $0.001^{\mathrm{ns}}$ \\
\hline Residual & 161 & 1.5 & 0.3 & 3.6 & 3.7 & 0.2 & 0.3 & 77 & 0.1 & 0.3 & 231 & 0.2 & 0 \\
\hline $\mathrm{CV}(\%)$ & & 32.1 & 32.7 & 2.9 & 53.2 & 30.0 & 22.6 & 12.0 & 24.1 & 25.7 & 9.2 & 28.0 & 0.0 \\
\hline $\mathrm{H}$ & & 0.90 & 0.10 & 0.80 & 0.40 & 0.00 & 0.80 & 0.80 & 0.20 & 0.30 & 0.90 & 0.00 & 0.60 \\
\hline$\% \mathrm{GEI}$ due to IF & CA1 & 61.5 & 54.6 & 62.4 & 86.4 & 74.9 & 75.5 & 56.6 & 85.4 & 59.2 & 57.9 & 81.5 & 68.2 \\
\hline$\%$ GEI due to IP & $\mathrm{CA} 2$ & 38.5 & 45.4 & 37.7 & 13.6 & 25.1 & 24.5 & 43.4 & 14.6 & 40.8 & 42.1 & 18.6 & 31.8 \\
\hline
\end{tabular}

Note. **, * highly significant $(\mathrm{P}<0.001),{ }^{*}$ significant $(\mathrm{P}<0.05)$ and ns non-significant $(\mathrm{P}>0.05)$.

The genotype variances were significant for all measured traits $(\mathrm{P}<0.05)$, indicating wide phenotypic variability among the single cross hybrids used in this study. The GEI mean squares varied significantly for grain yield, anthesis-silking interval, ear height, grain texture, plant height, Maize streak virus and ear position, except for Turcicum leaf blight, anthesis date and gray leaf spot where non-significant differences were observed. The highly significant variance of the environment for grain yield indicates its major contribution in influencing yield performance of maize.

The variation due to GEI was further split into two principal components, IPCA1 and IPCAII where IPCA1 was significant for all traits except TLB whereas IPCAII mean squares were non-significant for all traits except EH and PH. The first principal component axis (IPCAI) of the interaction of AMMI analysis accounted for $61.5 \%$ of the genotype $\times$ environment interaction sum of squares, the second principal component axis (IPCAII) accounted for 38.5 per cent using fifty five and fifty three degrees of freedom respectively. These two principal component axes (IPCA I and IPCAII) accounted for 100 per cent of the genotype $\times$ environment interaction sum of squares 
and used entire degrees of freedom available in the interaction. These results showed AMMI with two principal component axes (IPCAI and IPCAII) to be the best predictive model. Therefore, the significance of IPCA1 scores provided the necessary confidence for considering use of AMMI biplots for visual assessment of the genotype and location performances and their interactions (Gauch et al., 2008).

A large sum of squares for genotypes indicated that the genotypes were diverse with large differences among genotypic means causing variation in grain yield. The magnitude of the genotype $\times$ environment interaction sum of squares was 1.69 times larger than that for environments indicating that there were substantial differences in environmental response towards genotypes. The AMMI analysis for all traits showed that more than $50 \%$ of the variation in GEI mean squares (MS) was accounted for by IPCA1. Subsequently fitted IPCAs, notably IPCA2, were non-significant, indicating that they largely captured random error. These results compare well with those of Gauch (2006), which showed that significant IPCA1 and subsequent axes in AMMI capture interaction exclusively in a monotonic sequence that decreases from the largest component in the first axis to the smallest component in the last axis.

Table 3. Best performing genotypes from QPM single cross hybrids evaluated in three environments in Uganda

\begin{tabular}{|c|c|c|c|c|c|c|c|c|c|c|c|c|c|c|c|c|c|c|}
\hline Entry & Name & Pedigree & 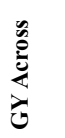 & 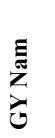 & $\sum_{0}^{\frac{\pi}{5}}$ & 茅 & ₹ & $\frac{5}{4}$ & 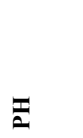 & $\underset{|r|}{\mid r}$ & $\stackrel{\dot{\theta}}{\stackrel{\dot{\theta}}{\dot{\pi}}}$ & $\underline{\exists}$ & 函 & 넌 & $\stackrel{n}{3}$ & 芯 & $\stackrel{\oplus}{\exists}$ & $\sum_{i}^{\infty}$ \\
\hline 29 & QPMSC-29 & $\begin{array}{l}\text { Pool15QPMFS538-B-3-B- } \\
\text { \#-5-3-1-B-B-B/CML511 }\end{array}$ & 7.06 & 6.17 & 7.95 & 5.42 & 63.79 & 4.01 & 192.5 & 87.6 & 0.5 & 2.2 & 1.8 & 1.1 & 2.0 & 0.6 & 1.5 & 1.3 \\
\hline 10 & QPMSC-10 & $\begin{array}{l}\text { Pool15QPMFS538-B-3-B- } \\
\text { \#-5-1-1-B-B-B/CML144 }\end{array}$ & 6.72 & 5.21 & 8.23 & 4.44 & 65.22 & 3.79 & 200.0 & 97.0 & 0.5 & 1.6 & 1.9 & 2.0 & 2.9 & 0.7 & 1.3 & 1.5 \\
\hline 18 & QPMSC-18 & $\begin{array}{l}\text { Pool15QPMFS538-B-3-B- } \\
\text { \#-5-1-4-B-B/CML511 }\end{array}$ & 6.59 & 5.58 & 7.60 & 4.69 & 65.34 & 2.71 & 182.0 & 82.2 & 0.4 & 1.6 & 2.0 & 1.4 & 2.3 & 1.0 & 1.2 & 1.2 \\
\hline 27 & QPMSC-27 & $\begin{array}{l}\text { Pool15QPMFS538-B-3-B- } \\
\text { \#-5-3-1-B-B-B/CML159 }\end{array}$ & 6.38 & 5.96 & 6.79 & 2.85 & 66.58 & 0.44 & 194.8 & 89.6 & 0.5 & 2.0 & 2.1 & 1.3 & 1.8 & 1.8 & 1.5 & 1.5 \\
\hline 51 & QPMSC-51 & $\begin{array}{l}\text { Pool15QPMFS538-B-3-B- } \\
\text { \#-7-5-1-B-B-B/QPM24 }\end{array}$ & 6.24 & 5.46 & 7.02 & 4.49 & 61.74 & 1.23 & 196.3 & 83.9 & 0.4 & 2.3 & 1.7 & 1.6 & 1.8 & 2.7 & 1.5 & 1.5 \\
\hline 11 & QPMSC-11 & $\begin{array}{l}\text { Pool15QPMFS538-B-3-B- } \\
\text { \#-5-1-1-B-B-B/CML159 }\end{array}$ & 6.13 & 5.12 & 7.14 & 3.39 & 65.36 & 1.96 & 184.37 & 87.4 & 0.5 & 1.4 & 1.9 & 1.4 & 2.0 & 0.9 & 1.5 & 1.4 \\
\hline 17 & QPMSC-17 & $\begin{array}{l}\text { Pool15QPMFS538-B-3-B- } \\
\#-5-1-4-B-B / C M L 181\end{array}$ & 6.01 & 5.92 & 6.09 & 3.76 & 65.66 & 2.49 & 172.18 & 69.3 & 0.4 & 2.6 & 2.0 & 1.1 & 2.0 & 1.1 & 1.5 & 1.4 \\
\hline 12 & QPMSC-12 & $\begin{array}{l}\text { Pool15QPMFS538-B-3-B- } \\
\text { \#-5-1-1-B-B-B/CML181 }\end{array}$ & 5.8 & 6.04 & 5.75 & 3.99 & 65.50 & 0.004 & 167.85 & 75.6 & 0.5 & 2.8 & 1.8 & 1.3 & 2.3 & 0.6 & 1.2 & 1.5 \\
\hline 46 & QPMSC-46 & $\begin{array}{l}\text { Pool15QPMFS538-B-3-B- } \\
\text { \#-7-4-1-B-B-B/CML181 }\end{array}$ & 5.65 & 5.19 & 6.11 & 6.09 & 65.189 & 1.27 & 168.65 & 75.9 & 0.4 & 2.7 & 2.3 & 1.3 & 2.9 & 1.6 & 1.5 & 1.6 \\
\hline 25 & QPMSC-25 & $\begin{array}{l}\text { Pool15QPMFS538-B-3-B- } \\
\text { \#-5-3-1-B-B-B/QPM24 }\end{array}$ & 5.64 & 5.14 & 6.14 & 4.91 & 63.58 & 2.26 & 177.06 & 77.3 & 0.4 & 2.1 & 1.8 & 1.8 & 2.3 & 2.2 & 1.5 & 2.0 \\
\hline 54 & Check 1 & Longe 5/CML511 & 5.60 & 4.49 & 6.71 & 4.28 & 65.29 & 2.03 & 187.73 & 86.9 & 0.5 & 2.4 & 1.9 & 1.5 & 2.3 & 1.1 & 1.5 & 1.8 \\
\hline \multirow[t]{3}{*}{55} & Check 2 & Longe $5 \mathrm{D}$ & 4.99 & 3.03 & 6.95 & & 61.7 & 5.6 & 164.9 & 75.3 & 0.47 & 1.7 & 2.2 & 2.3 & 2.4 & 1.0 & 1.5 & 2.2 \\
\hline & Mean & & 3.8 & 3.3 & 4.3 & 5.48 & 66.5 & 3.6 & 165.6 & 73.0 & 0.4 & 2.0 & 2.4 & 1.3 & 2.1 & 1.5 & 1.7 & 1.6 \\
\hline & LSD (0.05) & & 1.6 & 1.7 & 2.8 & 3.76 & 2.8 & 3.1 & 17.3 & 9.9 & 0.0 & 0.7 & 0.6 & 0.4 & 0.7 & 1.1 & 0.8 & 0.5 \\
\hline
\end{tabular}

The best performing genotypes from QPM single cross hybrids across the three environments in Uganda (Table 4) were QPMSC-29, QPMSC-10, QPMSC-18, QPMSC-27 and QPMSC-51. The selected hybrids outperformed the best check (Longe 5/CML511) which recorded $5.6 \mathrm{t} \mathrm{ha}^{-1}$. Overall mean performance showed that, QPMSC-29 performed best across environments followed by QPMSC-10.

Stability coefficient for genotype by environment was used to identify the most stable genotypes across environments. The more stability coefficient scores approximate to zero, the more stable the genotype is over all environments sampled. Accordingly, based on stability coefficients for genotype by environment, the most superior and stable single cross QPM hybrids across environments for yield was QPMSC-18 with stability coefficient (SC) of 0.20 followed by QPMSC-29 with SC of 0.46 (Table 4). The hybrids shown on Table 5 were found to be stable yielders across environments with high mean value for grain yield and could be recommended for advancement. 
Table 4. The best five QPM hybrids based on Stability coefficients (SC) for genotype by environment for grain yield (GY)

\begin{tabular}{llll}
\hline Stability Ranks & QPM Hybrids & GY & SC \\
\hline 1 & QPMSC-18 & 6.59 & 0.20 \\
2 & QPMSC-29 & 7.06 & 0.46 \\
3 & QPMSC-51 & 5.73 & 0.66 \\
4 & QPMSC-11 & 5.35 & 1.29 \\
5 & QPMSC-35 & 5.23 & 1.34 \\
\hline
\end{tabular}

In addition to AMMI, the genotype and genotype by environment interaction (GGE) biplot (Butran et al., 2004; Samonte et al., 2005) was also utilized to determine "which hybrid won where", possible existence of different mega environments and identify genotypes potentially suitable to specific mega-environments (Yan et al., 2000; Yan, 2001; Yan \& Rajcan, 2002).

The polygon view of a biplot is the best way to visualize the interaction patterns between genotypes and environments (Yan \& Rajcan, 2002; Yan \& Kang, 2003; Yan \& Tinker, 2006) (Figure 1). The polygon is formed by connecting the markers of genotypes that are further away from the biplot origin such that all genotypes are contained in the polygon. The genotypes which are located on vertices of the polygon formed are either the best or poorest in one or more environments (Yan et al., 2000; Yan \& Rajcan, 2002; Yan \& Tinker, 2006). Accordingly, the best vertex single cross QPM hybrids for grain yield were QPMSC-18 (18), QPMSC-29 (29), QPMSC-10 (10), QPMSC-12 (12), QPMSC-43 (43), and poorest hybrids were identified as QPMSC-9 (9), QPMSC-32 (32), QPMSC-22 (22), QPMSC-23 (23), QPMSC-19 (19) and QPMSC-55 (55).

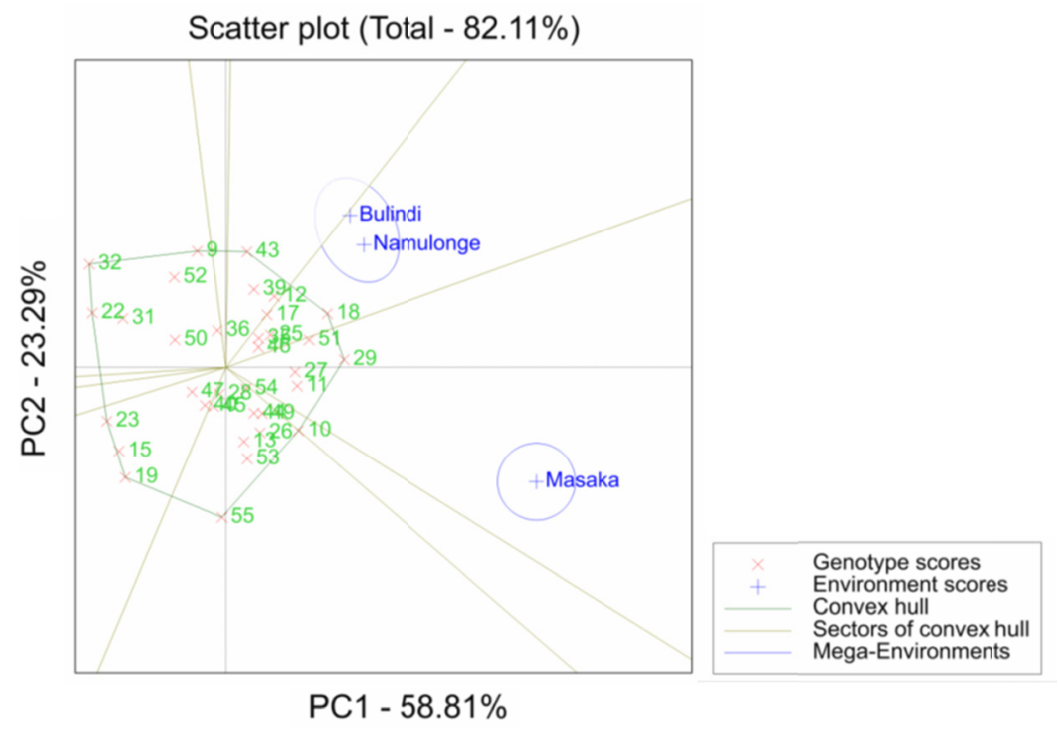

Figure 1. Polygon views of the GGE biplot based on symmetrical scaling for the "who-won-where" pattern of genotype and environments for grain yield (GY) for single cross

A biplot has four sections, depending upon signs of the genotypic and environmental scores. The IPCI scores of a genotype in the GGE analysis (Figure 1) are an indication of the stability of a genotype over environments. The greater the IPCI scores, either positive or negative, the more specifically adapted a genotype is to certain environments. The more IPCI scores approximate to zero, the more stable the genotype is over all environments sampled. The hybrids QPMSC-43 (43), QPMSC-12 (12), QPMSC-18(18) and QPMSC-29 (29) posed in quadrant two and recorded high mean with positive interaction indicating that they have specific adaptation to favorable environments. Considering only the IPCAI scores, it became clear that these hybrids were the more unstable genotypes, but they were well adapted to high yielding or more favorable environments.

Another important feature of GGE biplots is that they indicate environmental groupings, suggesting possible existence of different mega environments. In this study two mega environments are suggested for each trait 
evaluated. For grain yield, the first mega environment had environments Namulonge and Bulindi with QPM hybrids QPMSC-18, QPMSC-29, as the best performers and the second mega environment had Masaka with QPMSC-10 performing best for single cross hybrids (Figure 1). The ultimate goal of maize breeding programs focusing on various stress breeding is to increase and stabilize grain yield production. Uganda has diverse agro-ecological zones and maize varieties are bred for different zones. However, maize is grown in almost allpartsof the country, which are highly variable in rainfall, temperature and soil characteristics. Identifying widely adapted and stable genotypes across a wide range of environments is the most ideal way to minimize $(\mathrm{G} \times \mathrm{E})$ interactions although the presence of $\mathrm{G} \times \mathrm{E}$ interaction can be exploited by selecting superior genotypes for specific target environments (Ceccarelli, 1989). Accordingly, the selected QPM hybrids, QPMSC-18, QPMSC-29, and QPMSC-10 could be tested in more locations to minimize $(\mathrm{G} \times \mathrm{E})$ interactions.

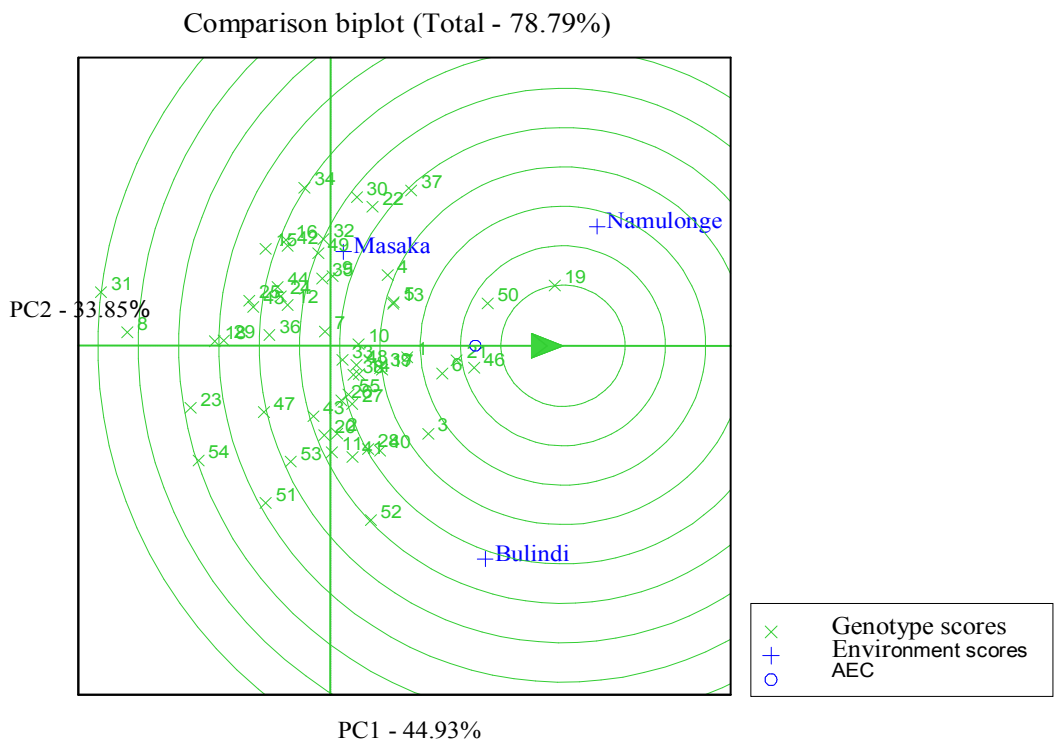

Figure 2. Ranking of genotypes relative to an ideal genotype

The ideal genotype can be used as a reference for genotype evaluation. An ideal genotype should have both high mean yield performance and high stability across environments (Kaya et al., 2006; Yan \& Tinker, 2006). In this study, QPMSC-19, QPMSC-50, QPMSC-46 and QPMSC-21 were ideal genotypes (the center of concentric circles) and genotypes located closer to the ideal genotypes are more desirable than the others (Figure 2). Of these, QPMSC-46 was earlier identified among the best across locations. Genotypes grouped in the concentric circle next to ideal genotype were more desirable. However, genotype QPMSC-31 and QPMSC-8 were undesirable. These models are reportedly useful to provide a valuable prediction assessment (Ezatollah et al., 2012). However, Becker and Léon (1988) stated that multivariate methods are too sophisticated to provide a simple measure of yield stability which allows a ranking of genotypes.

\section{Conclusions}

The results of genotypic effect for grain yield among new QPM hybrids presents an opportunity in selecting superior varieties for farmers. While the significant GEI effect can be explored to select hybrids that are stable across mega-environments as well as those suitable for specific ecologies, subsequent systematic evaluation of GEI effects for a given trait is useful for understanding varietal stability and hence strategic deployment of varieties to reduce variability in performance from one production environment to another. Five most stable hybrids, QPMSC-29 (29), QPMSC-10 (10), QPMSC-18 (18), QPMSC-27 (27) and QPMSC-51 (51) can be advanced in the variety release pipeline in Uganda. These hybrids could be tested in high-yield environments to ensure the consistency in yield performance for consideration for commercialization.

Two mega maize growing environments each consisting of different environments was established where the evaluations of the hybrids were made. Therefore, the maize breeding program of Uganda could consider these two mega environments separately in order to maximize the yield potential of maize and provide specific recommendation in the maize growing areas of the country. Moreover, additional yield trials may be required to 
better investigate the magnitude of GEI and yield stability of maize hybrids across all the maize growing agro-ecologies in multiple seasons in Uganda.

\section{Acknowledgements}

We greatly acknowledge Kyambogo University of Uganda for funding the research. National Crops Resources Research Institute (NaCRRI) Namulonge, Kampala, Uganda, is acknowledged for providing materials used in this study and for availing research facilities.

\section{References}

Acquaah, G. (2012). Principles of Plant Genetics and Breeding (2nd ed.). John Willey and Sons Ltd, UK. https://doi.org/10.1002/9781118313718

Annicchiarico, P. (2002). Genotype $\times$ environment interaction: Challenges and opportunities for plant breeding and cultivar recommendations. FAO Plant Prod. \& Prot. Paper 174. FAO United Nations, Rome.

Badu-Apraku, B., Fakorede, M. A. B., Oyekunle, M., Yallou, G. C., Obeng-Antwi, K., Haruna, A., \& Akinwale, R. O. (2015). Gains in grain yield of early maize cultivars developed during three breeding eras under multiple environments. Crop Science, 55, 527-539. https://doi.org/10.2135/cropsci2013.11.0783

Badu-Apraku, B., Oyekunle, M., Fakorede, M. A. B., Vroh, I., Akinwale, R. O., \& Aderounmu, M. (2013). Combining abilityheterotic patterns and genetic diversity of extra-early yellow inbred lines under contrasting environments. Euphytica, 192, 413-433. https://doi.org/10.1007/s10681-013-0876-4

Banziger, M., \& Vivek, B. S. (2007). Fieldbook: Software for Managing a Maize Breeding Program. CIMMYT.

Becker, H. C., \& Leon, J. (1988). Stability analysis in plant breeding. Plant Breeding, 101, 1-23. https://doi.org/ 10.1111/j.1439-0523.1988.tb00261.x

Butran, A., Velasco, P., Ordas, A., \& Malvar, R. A. (2004). Yield evaluation of maize cultivars across environments with different levels pink stem borer infestation. Crop Science, 44, 741-747. https://doi.org/ $10.2135 /$ cropsci2004.7410

Carangal, V. R., Alli, S. M., Koble, A. F., Rinke, E. H., \& Sentz, J. C. (1971). Comparison of S1 with testcross evaluation for recurrent selection in maize. Crop Sci., 11, 658-661. https://doi.org/10.2135/cropsci1971. 0011183X001100050016x

Ceccarelli, S. (1989). Wide adaptation: How wide? Euphytica, 40, 197-205.

CIMMYT. (1985). Managing Trials and Reporting Data for CIMMYT's International Maize Testing Program. Mexico, D.F.

Crossa, J. (1990). Statistical analyses of multi-location trials. Advances in Agronomy, 44, 55-85. https://doi.org/ 10.1016/S0065-2113(08)60818-4

Eberhart, S. A., \& Russell, W. A. (1966). Stability parameters for comparing varieties. Crop Science, 6, 36-40. https://doi.org/10.2135/cropsci1966.0011183X000600010011x

Ezatollah, F., Mohammadi, R., Aghaee, M., \& Vaisi, Z. (2012). GGE biplot analysis of genotype $\times$ environment interaction in wheat-barley disomic addition lines. Australian Journal of Crop Science, 6, 1074-1079.

Fan, X. M., Kang, M. S., Chen, H., Zhang, Y., Tan, J., \& Xu, C. (2007). Yield stability of maize hybrids evaluated in multi-environment trials in Yunnan, China. Agron. J., 99, 220-228. https://doi.org/10.2134/ agronj2006.0144

Farshadfar, E., Mohammadi, R., Aghaee, M., \& Vaisi, Z. (2012). GGE biplot analysis of genotype .environment interaction in wheat-barley disomic addition lines. Australian Journal of Crop Science, 6, 1074-1079.

Farshadfar, E., Rashidi, M., Mahdi, M. J., \& Zali, H. (2013). GGE biplot analysis of genotype $\times$ environment interaction in chickpea genotypes. Eur. J. Exp. Biol., 3, 417-427.

Gauch, H. G. (2006). Statistical analysis of yield trials by AMMI and GGE. Crop Science, 46, 1488-1500. https://doi.org/10.2135/cropsci2005.07-0193

Gauch, H. G. (2013). A simple protocol for AMMI analysis of yield trials. Crop Science, 52, $1860-1869$. https://doi.org/10.2135/cropsci2013.04.0241

Gauch, H. G., Piepho, H., \& Annicchiarico, P. (2008). Statistical analysis of yield trials by AMMI and GGE: further considerations. Crop Science, 48, 866-889. https://doi.org/10.2135/cropsci2007.09.0513 
Haggblade, S., \& Dewina, R. (2010). Staple food prices in Uganda.Variation in staple food prices: Causes, consequence, and policy options. African Agricultural Marketing Project (AAMP) (pp. 25-26).

Hongyu, K., Gracia-Pena, M., Araujo, L. B., \& Dias, C. T. S.,(2014). Statistical analysis of yield trials by AMMI analysis of genotype $\times$ environment interaction. Bio. Lett., 51, 89-102. https://doi.org/10.2478/ bile-2014-0007

Kang, M. S., Balzarini, M. G., \& Guerra, J. L. L. (2004). Genotype-by-environment interaction. In A. M. Saxton (Ed.), Genetic analysis of complex traits using SAS (pp. 69-96). SAS Publ., SAS Instt. Cary, NC.

Kaya, Y., Akcura, M., \& Taner, S. (2006). GGE-biplot analysis of multi-environment yield trials in bread wheat. Turkish Journal of Agriculture and Forestry, 30, 325-337.

Mohamed, N. E. M., Said, A. A., \& Amein, K. A. (2013). Additive main effects and multiplicative interaction (AMMI) and GGE-biplot analysis of genotype $\times$ environment interactions for grain yield in bread wheat (Triticum aestivum L.). African Journal of Agricultural Research, 8, 5197-5203.

Payne, R. W., Murray, D. A., Harding, S. A., Baird, D. B., \& Soutar, D. M. (2008). GenStat for Windows (11th ed.) Introduction. VSN International, Hempstead.

Piepho, H. P. (1994). Best linear unbiased prediction (BLUP) for regional yield trials: A comparison to additive main effects and multiplicative interaction (AMMI) analysis. Theor. Appl. Genat., 89, 647-654. https://doi.org/10.1007/BF00222462

Rao, P. S., Reddy, P. S., Rathore, A., Reddy, B. V. S., \& Panwar, S. (2011). Application of GGE biplot and AMMI model to evaluate sweet sorghum (Sorghum bicolor) hybrids for genotype $\times$ environment interaction and seasonal adaptation. Indian J. Agric. Sci., 81, 348-444.

Samonte, S. O. P. B., Wilson, L. T., McClung, A. M., \& Medley, J. C. (2005). Targeting cultivars onto rice growing environments using AMMI and SREG GGE biplot analysis. Crop Science, 45, 2414-2424. https://doi.org/10.2135/cropsci2004.0627

Yan, W. (2001). GGE biplot-A windows application for graphical analysis of multi-environment trial data and other types of two way data. Agronomy Journal, 93, 1111-1118. https://doi.org/10.2134/agronj2001. 9351111x

Yan, W. (2002). Singular value partitioning in biplot analysis of multi-environment trial data. Agronomy Journal, 94, 990-996. https://doi.org/10.2134/agronj2002.0990

Yan, W., \& Kang, M. S. (2002). GGE Biplot Analysis: A Graphical Tool for Breeders, Geneticists and Agronomists. CRC Press, New York. https://doi.org/10.1201/9781420040371

Yan, W., \& Kang, M. S. (2003). GGE biplot analysis: A graphical tool for Breeders, Geneticist and Agronomist. CRC press LLC, Boca Roton, Florida, USA.

Yan, W., \& Rajcan, I. (2002). Biplot analysis of test sites and traitrelations of soybean in Ontario.Crop Science, 42, 11-20. https://doi.org/10.2135/cropsci2002.1100

Yan, W., \& Tinker, N. (2006). Biplot analysis of multi-environment trial data: principles and applications. Can. J. Plant Sci., 86, 623-645. https://doi.org/10.4141/P05-169

Yan, W., Hunt, L. A., Qinglai, S., \& Szalvincs, K. (2000). Cultivar evaluation and megaenvironment investigation based on the GGE biplot. Crop Science, 40, 597-605. https://doi.org/10.2135/cropsci2000. $403597 x$

Ye, D., McNeil, D. L, \& Hill, G. D. (2013). Methods for analysing multi-site plant variety trials II. Selection for yield and stability. Agron. Soc. N. Z., 31, 25-33.

Zobel, R. W., Wright, M. J., \& Gauch, H. G. Jr. (1988). Statistical analysis of yield trials. Agron. J., 80, 388-393. https://doi.org/10.2134/agronj1988.00021962008000030002x

\section{Copyrights}

Copyright for this article is retained by the author (s), with first publication rights granted to the journal.

This is an open-access article distributed under the terms and conditions of the Creative Commons Attribution license (http://creativecommons.org/licenses/by/4.0/). 